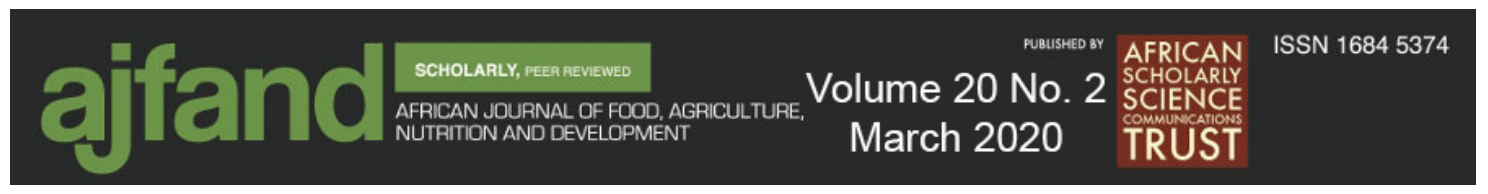

Afr. J. Food Agric. Nutr. Dev. 2020; 20(2): 15490-15508

DOI: 10.18697/ajfand.90.18275

\title{
DIETARY DIVERSITY OF REPRODUCTIVE AGE WOMEN IN THREE
} SOUTH-EASTERN STATES OF NIGERIA

\section{GN Onyeji ${ }^{1 *}$ and RA Sanusi²}

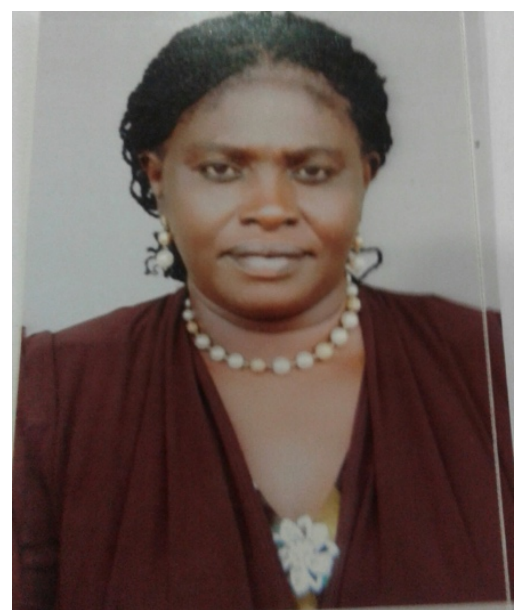

Gertrude Nneka Onyeji

*Corresponding author email: gnonyeji@yahoo.com

${ }^{1}$ Department of medical Biochemistry, Faculty of Basic Medical sciences, Alex Ekwueme Federal University Ndufu-Alike, Nigeria

${ }^{2}$ Department of Human Nutrition, College of Medicine, University of Ibadan, Ibadan, Nigeria 


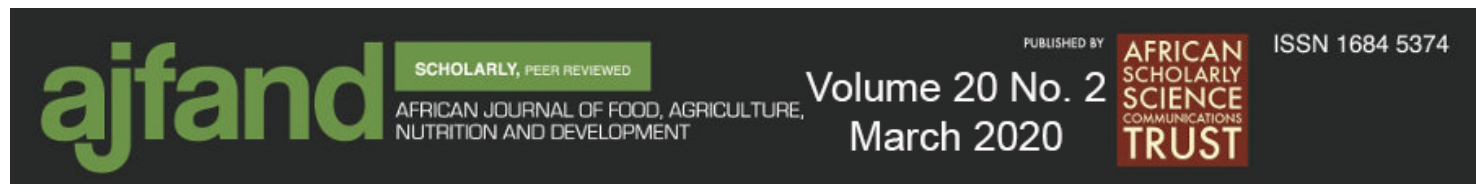

\begin{abstract}
Malnutrition has been an important public health problem in developing countries, especially among women of reproductive age. Dietary diversity and favorable nutritional status have been demonstrated to have a relationship with the quality of diets. Diets that are low in fat and sugars and rich in fruits, vegetables, and wholegrain foods may help reduce the risk of chronic diseases. Information on dietary intakes and dietary diversity of women across Nigeria is scarce. This study was conducted to assess dietary diversity, of diets of women of reproductive age in the South-eastern States of Nigeria. This study was descriptive cross-sectional in design with a four-stage sampling technique used to select women of reproductive age from three of the five states in the South-eastern States of Nigeria. Three Local Government Areas were randomly selected from the three senatorial districts of each state. From the nine Local Government Areas, 36 rural and 18 urban communities were randomly selected. A total of 1200 women of reproductive age 15-50 years participated in the study after giving informed consent. A pretested semistructured interviewer-administered questionnaire was used to collect data on demographic and socio-economic characteristics. Multiple 24-hour diet recall, weight and height measurements were conducted. The nutritional status of the respondents was assessed with the use of anthropometric indices, weight $(\mathrm{kg})$ and height $(\mathrm{m})$ to estimate the Body Mass Index (BMI), which was classified as underweight $\left(<18.5 \mathrm{~kg} / \mathrm{m}^{2}\right)$, normal $\left(18.5-24.9 \mathrm{~kg} / \mathrm{m}^{2}\right)$, overweight $\left(25.0-29.9 \mathrm{~kg} / \mathrm{m}^{2}\right)$ and obese $\left(\geq 30.0 \mathrm{~kg} / \mathrm{m}^{2}\right)$. Dietary diversity was determined using a 14 food-group dietary diversity tool and terciles were created to categorize individual dietary diversity (low: 1-4; average: 5-9; high: 10-14). The mean age of women participants was $28.2 \pm 5.6$ years and BMI was $26.8 \pm 4.8 \mathrm{~kg} / \mathrm{m}^{2}$. Most (96.3\%) women of reproductive age were married; $41.7 \%$ were traders while $54.9 \%$ completed secondary school education. Overall Dietary Diversity Score (DDS) was 7.0 \pm 1.8 and $7.6 \%$ scored low, $84.6 \%$ average, and $7.8 \%$ high. Overall DDS in the three states were similar $(p>0.05)$, however, the percentage with the low score was significantly higher in the rural sector $(9.8 \%)$ compared to the urban sector $(3.0 \%)$. Average dietary diversity found in these states indicates the average variety in dietary intake. Therefore, to enhance dietary diversity in Nigeria, public health messages should encourage and emphasize the production and consumption of diverse foods.
\end{abstract}

Key words: Dietary Diversity, Diet Recall, Women, Reproductive age, South-eastern Nigeria 


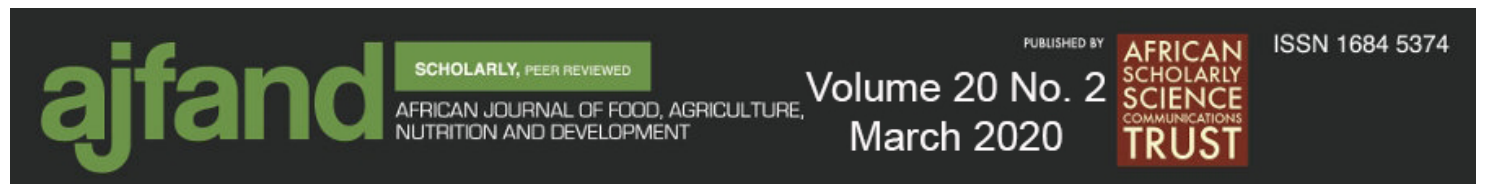

\section{INTRODUCTION}

Diverse diets refer to a variety of foods from different food groups (vegetables, fruits, grains, and animal source foods), which provide a balance of nutrients that promote healthy growth and development [1]. The increase in the variety of foods across and within food groups has the potential to ensure adequate intake of essential nutrients to promote good health [1]. Dietary Diversity (DD) is a parameter used in studies on human nutrition to quantify the different foods or food groups that have been consumed over a given period of time [2]. DD also gives an indication of the quality of the total diet in addition to having a positive association with nutritional adequacy $[3,4]$.

Dietary recommendations encourage increased dietary diversity following the recognition that dietary factors are linked with higher risks of chronic diseases. Also, other measures such as a reduction in intake of selected nutrients including fat, refined sugars and salt are part of dietary recommendations that are being promoted [2].

Poor populations from the developing world are seriously affected by lack of dietary diversity because their diets, which are principally based on starchy staples, contain little or no animal products with minimal fresh fruits and vegetables [5]. The micronutrients content of these plant-derived diets tend to be low and not in a form that is easily absorbed. Lack of adequate nutrients in diets for desirable body growth translates to unfavorable human health outcomes [6].

Consumption of non-diversified diets is associated with negative consequences on an individual's health, development and well-being. These negative effects are caused by a reduction in physical and social capacities, resistance to infection and impairment of cognitive development [7]. Literature is replete with studies indicating that women, predominantly those in the rural areas have poor nutrient intakes [8]. A foremost predisposing factor to morbidity and mortality among African women is maternal malnutrition and this is mainly caused by poor diet quality, inadequate food intake and recurrent infections [9]. Generally, poor micronutrient status among women is a global problem, which is most severe for poor women [10]. Evaluation of the extent of dietary diversity provides an avenue for assessing the quality of total diet $[3,11]$.

Studies on DD in Nigeria have focused more on households $[12,13]$ and only a very few are available that assessed diet diversity and quality of diets of Women of Reproductive Age (WRA) [14, 15]. The study of dietary diversity in food consumption among women of childbearing age in South-east Nigeria is scarce. This study was, therefore, designed to assess the dietary diversity and nutritional status of WRA in the South-eastern States of Nigeria.

\section{METHODOLOGY}

Study design and location: This study was a descriptive cross-sectional in design and a four-stage random sampling technique was used to select mothers from three of five states in South-eastern States of Nigeria. This study was carried out in three selected states in the South-east geo-political zone of Nigeria. The South-east geopolitical zone 


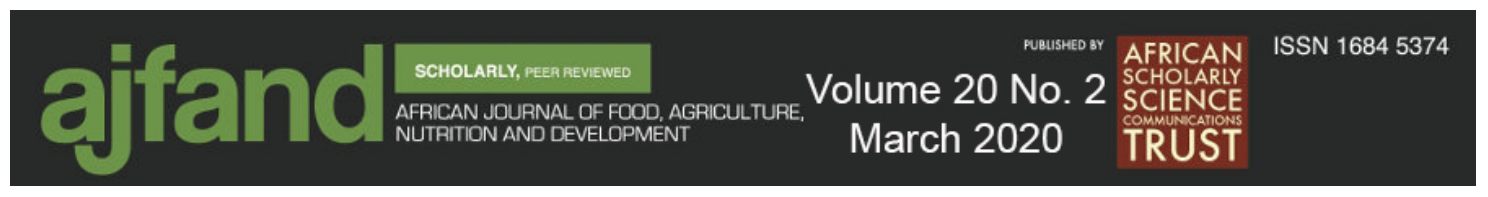

is made up of five states, namely Imo, Enugu, Anambra, Ebonyi, and Abia, with each state made up of three senatorial zones. Using random sampling by balloting of old East Central State, Anambra, Enugu, and Imo states were selected for this study. In each of the States, three senatorial zones were selected totaling nine senatorial zones. Within each state, three Local Government Areas were selected from each of the senatorial zone using a simple random sampling technique. In each of the Local Government Areas, communities were chosen based on population density to represent rural and urban settings in a ratio of $3: 1(267: 133)$. Nigeria is described as $75 \%$ rural [16]. Rural communities (36), and urban communities (18) were selected using a simple random sampling technique. Using systematic random sampling, every third household in the list was chosen for the study (the very first household was selected by using a table of random numbers) from a list of the number of eligible households identified in each Local Government Area during the house listing exercise in the enumeration areas. Any selected household that was inaccessible during the data collection was replaced with the next eligible household on the list. A total of 1,200 respondents (households) were selected, one woman aged between 15-50 years in each household with an under-five child was selected. The purpose of the study was explained to the women and informed consent received and consent forms were dully filled and signed by the subjects. Participants (women) were informed of their freedom to withdraw, or refuse to take part in the study without prejudice. Research assistants were persons resident within the states who have completed or still undergoing undergraduate training. The ethical clearance to carry out the project was given by the ethics committee of the College of Medicine University of Ibadan. Interviews were conducted in both English and Ibo (the local dialect) languages. Data collection was carried out from October 2010 to April 2011.

Subjects and sample size- Minimum sample size was determined using the formula for cross -sectional studies [17].

$$
\mathrm{n}=\frac{\mathrm{Z}^{2} \mathrm{pq}}{\mathrm{d}^{2}}
$$

Where:

$\mathrm{n}=$ minimum sample size when sample frame is more than 10,000 .

$\mathrm{Z}=\quad 1.96$ the standard normal deviate (or confidence coefficients), which corresponds to the confidence level adopted.

$\mathrm{d}=5 \%$ degree of accuracy desired (Tolerance error)

$\mathrm{p}=$ the target population estimated to have a particular Characteristic (if there is no reasonable estimate $50 \%$ is used).

$\mathrm{Q}=1-\mathrm{p}(50 \%$ unaffected population).

$\mathrm{Z}=1.96$ (That is a table of confidence coefficients for confidence levels in [18].

The estimated proportion of success (of accepting the various null hypotheses) $=50 \%$

Therefore,

$\mathrm{n}=\frac{\mathrm{Z}^{2} \mathrm{pq}}{\mathrm{d}^{2}}=\frac{1.96^{2}(0.5)(0.5)}{0.05^{2}}$

$=384$ 


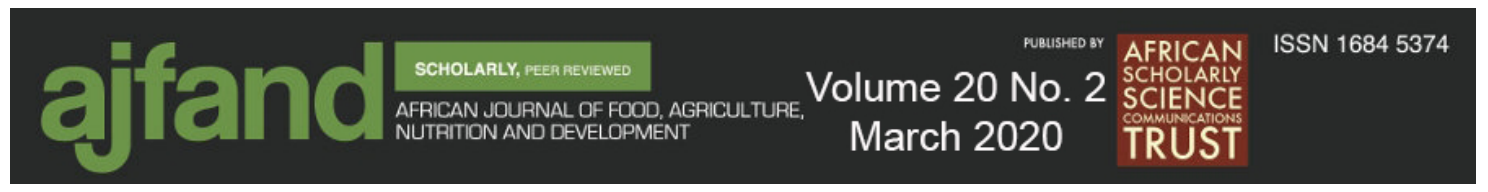

The sample size (n) for the study should, therefore, be three hundred and eighty four citizens. The sample size was increased to 400 subjects per state, for three states making it a total of 1200 subjects. The minimum sample size was calculated to be 1152; however, a total of 1200 subjects participated in the study.

\section{Inclusion criteria}

The study included all women of child-bearing age (15-50 years), who had children under 5 years of age, who gave informed consent to participate in the study, were healthy and not on medication, who had been resident in that location for the past three years, whose consumption was not affected by ill-health, fasting, national holidays, and festive celebrations.

Data collection: Information used in this study was collected by means of an interviewer-administered questionnaire. The data collected are presented below.

Demographic and socio-economic factors: The following demographic and socioeconomic factors were considered in this study: household identification, household composition, household size, age and religion. The others were the highest educational level attained by the respondents, the primary occupation of the respondents, and the method of refuse disposal, estimated monthly income of the household head and types of household equipment.

Dietary assessment: To obtain information on the subjects' food intake, trained interviewers were employed and they conducted an interview on 24-hour dietary recall. This involved requesting the subjects to recall all foods and beverages that they took within the previous 24 hours prior to the interview.

Dietary diversity: Dietary Diversity Score (DDS) was assessed from the information collected from the 24-hour dietary recall of the subjects, using a scale of fourteen food groups according to FAO guidelines for measuring individual DD [19]. The DDS described in these guidelines consist of a simple count of food groups that a household or an individual has consumed over the preceding 24 hours. The first fourteen food groups were used for the individual DD assessments [19]. To calculate the DDS for each individual, a point was awarded to each of the fourteen food groups consumed over the reference period, and all the points were totaled for the individual. Another parameter derived from the 14 food groups was dietary diversity terciles by categorizing the food groups into low, medium and high dietary diversity terciles. Individual DDs were considered based on their position on the scale.

Anthropometric measurements: Heights of women were measured in meters using the standiometer. Weights were measured in Kilogram $(\mathrm{kg})$ using a sensitive weighing bathroom scale (Hana bathroom scale). Individual heights and weights were then used to calculate Body Mass Index [BMI $=$ Weight $\left./ \mathrm{Height}^{2}\right]$. 


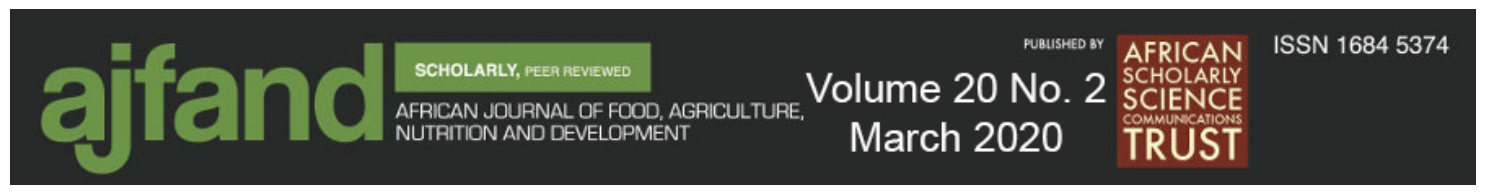

Statistical analysis: The Statistical Package for Social Sciences (SPSS version 17) was used in analyzing all the data. The transform and compute section of the SPSS package was used in deriving the DDS for each individual. The mean DDS for the different States and local government areas were compared using two-way Analysis of Variance (ANOVA), while the independent sample t-test was used to compare the mean DDS between urban and rural sectors. Association between DDS and socio-demographic factors was tested using Pearson chi-square.

\section{RESULTS AND DISCUSSION}

The characteristics of WRA that participated in this study are shown in Table 1. Eight hundred and eighty three $(66.9 \%)$ were from rural areas and $397(33.1 \%)$ from urban areas. The mean age of the subjects was $28.22 \pm 5.58$ years; the mean height, weight, and BMI were $1.60 \pm 0.08 \mathrm{~m}, 69.11 \pm 13.89 \mathrm{~kg}$ and $26.81 \pm 4.82$, respectively. The prevalence of overweight and obesity were $39.3 \%$ and $21.5 \%$, respectively. The minimum family size was two, while the maximum was 15 with a mean of $5.02 \pm 1.77$ person in the household. A large proportion of the women $(96.3 \%)$ were married, while about $54.9 \%$ and $28.5 \%$ completed secondary school and tertiary education respectively. The predominant occupation for the head of households included: trading $(41.7 \%)$, employed by the government (14.3\%), artisans (5.27\%) and unemployed (25.7\%). The predominant occupation for the head of households included: trading $(39.8 \%)$, employed by the government (19.1\%) and artisans (15.4\%). Up to $60.9 \%$ of the respondents had no idea of the head of the household's income. About $26.0 \%$ of heads of households earned between $\$ 5,000$ and $\$ 34,999$ (\$31 and \$216) while 107 (8.9\%) earned $\$ 45,000$ (\$277) and above. About $45.7 \%$ of the respondents reported monthly income of between $₫ 5$, 000 and $\$ 44,999$ (\$31 and \$277), 2.7\% earned $\$ 45,000$ (\$277) and above, while 23.2\% had no idea of their income (Table 1).

Table 2 shows that the predominant food groups in the diet of the South-east were cereal/grains $(92.0 \%)$, white tuber $(78.7 \%)$, dark green vegetables $(55.2 \%)$, legumes and nuts $(53.8 \%)$, milk products $(52.8 \%)$, vitamin A vegetables $(47.6 \%)$. While a large majority $(98.0 \%)$ consumed oils/fat in soups and stew. Overall, oils and fat $(98 \%)$, cereals/grains (92\%), white roots and tubers $(78.7 \%)$, fish $(76.6 \%)$ constituted the predominant food groups mostly consumed in the study area. Legumes/nuts $(53.8 \%)$, dark green vegetables $(55.2 \%)$, milk/milk products $(52.8 \%)$ were consumed moderately. Few women reported the use of vitamin A fruits (10.5\%), other fruits (18.0\%), organ meat $(1.8 \%)$, eggs $(6.5 \%)$. Comparison of food groups' consumption from the different states, revealed that the majority $(92.0 \%)$ of the subjects from the three states consumed foods from cereal products. The consumption of white roots and tubers was higher in Imo (84.8\%) and Anambra (81.8\%) than Enugu (69.5\%). Over $46 \%$ of women in Imo and Anambra consumed food rich in vitamin A vegetables as against 38\% from Enugu. Enugu women consumed less dark green vegetables $(35.5 \%)$ than Imo $(75.2 \%)$ and Anambra (55.2\%). Imo women consumed more of other vegetables $(42.8 \%)$ compared to Enugu (30.8\%) and Anambra (25.0\%). Over 50\% from each state consumed flesh meat. Imo women consumed fish most (86.5\%), followed by Anambra women $(73.0 \%)$ and Enugu (70.2\%). Over 50\% of women in the three states consumed legumes and nuts. Few women reported the use of vitamin A fruits (10.5\%), other fruits (18.0\%), organ 


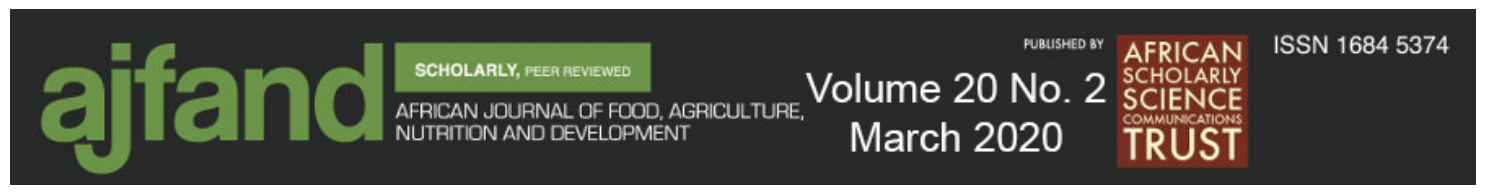

meat (1.8\%), eggs (6.5\%). Enugu women consumed less milk (45.2\%) compared to Imo $(57.8 \%)$ and Anambra (52.8\%).

Different studies have confirmed that diverse diets are associated with health benefits including protection against chronic diseases such as cancer [20, 21], prolonged longevity [22] and improved health status [23]. For an individual to achieve optimal nutritional status, he/she has to consume foods from different food groups. In this study, the commonly consumed food groups, other than palm oil were cereals, roots, and tubers while fruits, eggs, vegetables, organ meat, legumes, milk, and meat, were consumed the least often (Table 2). The results are consistent with the study of Arimond and Ruel [5] who reported that lack of dietary diversity is specifically a big problem among populations in the developing world where diets are based principally on mostly starchy foods and often include only a few animal products. Palm oil contributed to a high intake of vitamin A, because it was the main oil used in the preparation of stews, soups, and pottages by families in Nigeria. The high intake of cereals, roots, and tubers indicated that they were the predominantly grown staple in these states and the majority of the women chose diets based on the available foods. Few women reported the use of vitamin A fruits $(10.5 \%)$, other fruits $(18.0 \%)$, organ meat $(1.8 \%)$, and eggs $(6.5 \%)$.

Lack of diversity in the diet is strongly associated with inadequate intake and risks of deficiencies of essential micronutrients [24] and over-consumption of cereals, roots and tubers without corresponding intake of protein, legumes, fruit, and vegetables. It could also result in protein deficiency and micronutrient deficiency. The low consumption of legumes, fruits, and vegetables, three valuable sources of micronutrients, suggests a lowquality diet in South-east Nigeria. In addition, the limited access to nutritious foods like eggs, milk and milk products, organ meat, fruit, vegetables, legumes and nuts in the study area could be attributed to economic constraints and lack of knowledge and information [25] and this could predispose the women to deficiencies in protein, vitamin A, iron, and calcium. Micronutrient deficiencies have adverse effects on human health and nutrition $[26,27]$. Children and women of reproductive age are especially vulnerable because they have particularly high micronutrient requirements [24, 27].

Table 3 shows that the minimum DDS in this study was 2 while the maximum value was 11 and in the states, the percentage that scored low, medium and high were higher in Anambra state. In the South-east, a total of $84.6 \%$ scored average DDS of 5-9 having the highest frequency, followed by high DDS with $7.8 \%$ of the subjects. The least frequency was recorded for low DDS by $7.6 \%$ of the subjects. Urban recorded $3.0 \%$ on the low category, $89.2 \%$ on medium and $7.8 \%$ on high while rural recorded $9.8 \%$ on the low category, $82.3 \%$ on medium and $7.8 \%$ on high.

One of the ways of defining cut-off points for evaluating varying levels of dietary diversities in population is by the creation of terciles and sometimes quintiles [2]. A scale of dietary diversity terciles was generated based on the 14 food groups, to find out the proportion of subjects scoring low, medium and high DDS (Table 3). The results from this study showed that more than $80 \%$ of the women fell in the medium tercile and consumed between 5-9 food groups. 


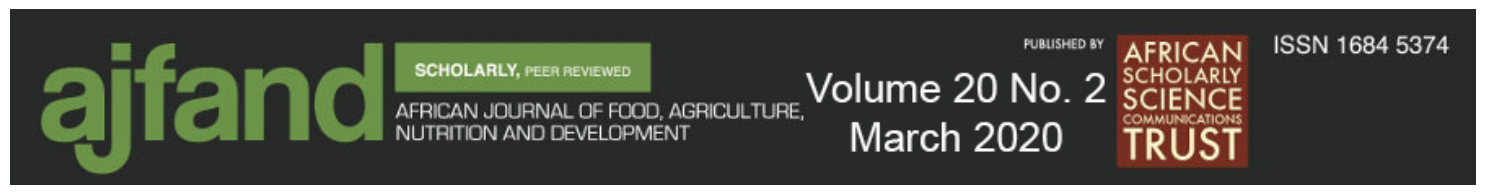

Table 4 showed that the mean DDS for South-east was $6.96 \pm 1.80$. Imo, Enugu and Anambra States had mean DDS of $7.10 \pm 1.99,6.89 \pm 1.78$ and $6.89 \pm 1.62$, respectively. There was no significant difference observed in DDS among states $(\mathrm{p}>0.05)$. The mean DDS for urban was $7.04 \pm 2.52$ and rural $6.90 \pm 2.43$. A t-test revealed a significant mean difference between sectors $(\mathrm{t}=6.23, \mathrm{p}<.001)$. Urban with a mean DDS of 7.04 (2.52) was higher than rural with a mean value of 6.90 (2.43).

The mean DDS of $6.96 \pm 1.80$ for South-east was higher than the values from other parts of Nigeria. These studies showed DDS of 5.81 for women in six Nigerian States [14], 4.07 for males and 4.53 for females in South-west Nigeria [28], 4.6 in North-Central Nigeria [29] and 2.94 in Abia State [30]. Studies in other developing countries that have evaluated their DDS showed a lower mean diversity of 3.6 for South African children [31], 4.02 for South African adults [32] and 4.6 for Burkina Faso diet [33]. Even though the DDS of the South-east was higher than some of these studies from Nigeria and other developing countries, it was still low when assessed using 14 food groups over the reference period. It is evident that poor DD is a characteristic feature of many developing countries. This might probably be due to economic constraints such that they are unable to afford many food varieties, ignorance of the importance of consumption of different food groups and lack of adequate nutrition information.

Arroyo et al. [34] in their study reported that sector residence was important for dietary diversity. A t-test revealed a significant mean difference between sectors $(t=6.23$, $\mathrm{p}<.001)$.

Urban with a mean DDS of 7.04 (2.52) was higher than rural with a mean value of 6.90 (2.43) (Table 4). This is in line with the finding of an earlier study conducted in Botswana [35], which reported that the diet of older persons who lived in urban areas and had cattle and higher education had a greater food variety than diets of older people living in rural areas, but in contrast with the findings of Sanusi [14] and Delisle [36]. Urbanization translates into change in lifestyles associated with higher income levels, consumption of more diverse food because of increased food choices in markets, accompanied by a taste for new foods, and time constraints due to women's employment [37]. Variety is often much greater in urban and peri-urban centers where food markets are vastly supplied and easily accessible [38]. Arimond and Ruel [39] reported that an increase in dietary diversity helps individuals to meet their daily requirements for many essential nutrients. In other words, improvement in dietary diversity of individuals can ensure their nutritional adequacy. Measurement of dietary diversity of a country is important as this affects the health and nutrition of individuals in that country, especially women of reproductive age and children. To enhance DD in South-east Nigeria, public health messages should emphasize the improvement in household and individual dietary diversity.

There was a negative correlation between DDS and BMI in this study $(r=-12, p>0.05)$ (Table 5). This is consistent with the study of previous findings by Sanusi [14], Labadarios et al. [31] and Savy et al. [40] as against other studies [5, 41, 42] that have established a direct relationship between DDS and nutritional status in different age groups. Body mass index measures nutritional status while DDS measures adequate 


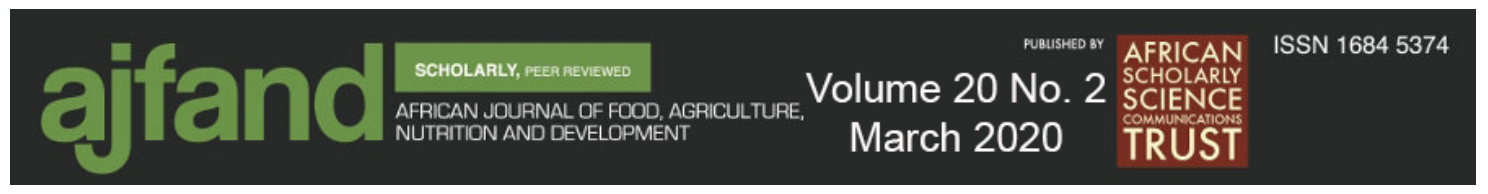

nutrient intake $[32,42]$. Obesity and overweight in the population studied was high. This could be a result of a high intake of cereals, white tubers and roots coupled with sedentary lifestyles.

This study tried to find out the relationship between DD and some parameters like family size, family income, socio-economic status, education, occupation and sector (urban and rural). Even though there was no significant mean difference observed among different groups of family sizes and DD ( $p>0.50)$, family sizes of between $1-4(45.8 \%)$ and $5-8$ $(50.0 \%)$ had higher DDS. This means that the smaller the family size the higher the dietary diversity. The results are consistent with the study of Ishara et al. [43] who reported that the larger the family size, the lower the household calorie adequacy ratio. This finding could be explained by considering the high cost of providing for large families than smaller families. Smaller families could be able to afford diverse varieties of foods since the provision for small families would be easier with less income.

The result also showed that the income of the respondent had a significant positive effect on the DDS of the family $(\mathrm{p}<0.05)$. This is corroborated by the findings of other investigators [44] who reported that the income of mothers had a significant positive-effect on the caloric intake of the household, mother, and children. More diverse diets and better access to health care and better environmental conditions are enjoyed by families with higher incomes and resources [5]. The increase in consumption of more diverse diets as a result of an increase in income may lead to an improvement in the micronutrient composition of the diet. Although DDS were higher in the socio-economic status of medium and high compared to values in the low socio-economic status, there was no significant difference between DDS terciles for subjects from different socioeconomic status $(\mathrm{p}>0.05)$. This finding is contrary to the reports of Savy et al. [40] that showed an increase in dietary diversity between households from different socioeconomic statuses in their study.

There was no significant mean difference observed in DDS terciles in different groups of educational attainment of respondents. The government employed only $14.3 \%$ of the subjects. Most of the respondents had low educational levels; therefore, they were unemployed, petty traders, working in their husbands' shops or doing low-paying jobs. Many women with lower educational status did not have any source of income though they joined their husbands in their businesses.

\section{CONCLUSION}

This study has established average/medium dietary diversity in the three states of Southeast Nigeria and limited access to nutritious food like eggs, milk and milk products, organ meat, fruit, vegetables, legumes and nuts. High dietary diversity is important to ensure that women have adequate diets to maintain good nutritional status. Therefore, to enhance dietary diversity in Nigeria, public health messages on nutrition should encourage and emphasize the production and consumption of diverse foods to maintain good nutritional status and appropriately control the prevalence of overweight and obesity among women of reproductive age. 


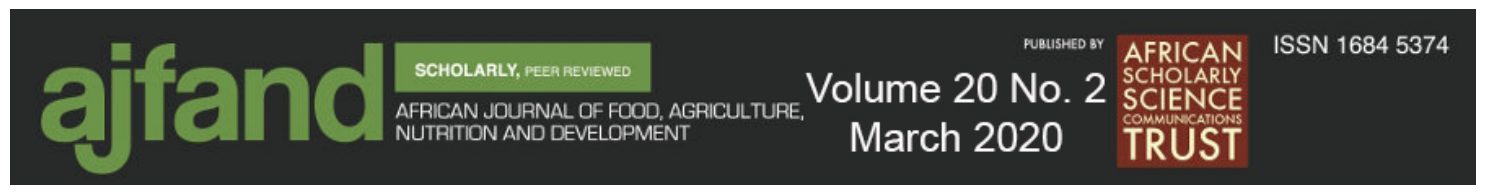

\section{Limitation}

The respondents in this study included only women in three states out of the five states that make up South-east Nigeria during the period of data collection and, thus, may not be representative of all women of reproductive age in Nigeria. However, this paper has revealed the DD of women of reproductive age in South-east Nigeria.

\section{ACKNOWLEDGEMENT}

Our gratitude goes to the staff of the local government authorities and the communities for their support to conduct the study and to the subjects for providing the required information. We would also want to thank the field officers and their supervisors for their cooperation.

\section{Funding}

The study was self funded.

\section{Authors' contributions}

GN carried out the data collection, data analysis and interpretation and drafted the manuscript; RA contributed to the project design, supervised and corrected the project. All authors have read and approved the manuscript and made their contributions to improve the manuscript.

\section{Competing interest}

The authors declare that there are no competing interests.

\section{Consent for publication}

Consent for publication is not necessary because this manuscript does not have personal data like individual details, images or videos.

\section{Data and material availability}

I declare that the data and material for this manuscript are available.

\section{Ethics approval and consent to participate}

Ethical clearance was given by the University of Ibadan/University College Hospital (UI/UCH) Ethics Committee, College of Medicine University of Ibadan. The evidence that the appropriate Ethics Committee was satisfied and approved this study is attached to the manuscript. Permission also was obtained from the Local Government Chairmen and the community Chiefs. The purpose of the study was explained to the women who gave their consent and also dully filled the informed consent forms. Participants (women) were informed of their freedom to withdraw or refuse to take part in the study without prejudice. Some declined after explanation. 


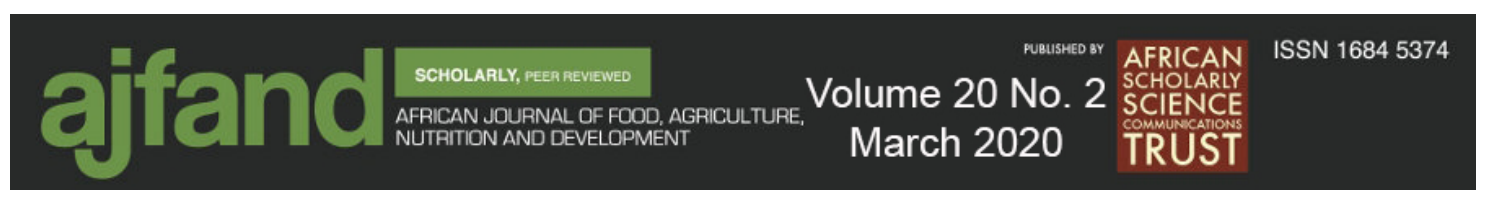

Table 1: Socio-demographic characteristics of subjects

\begin{tabular}{llllc}
\hline Variables & $\begin{array}{l}\text { Imo } \\
(\mathbf{\%})\end{array}$ & $\begin{array}{c}\text { Enugu } \\
(\mathbf{\%})\end{array}$ & $\begin{array}{c}\text { Anambra } \\
(\mathbf{\%})\end{array}$ & $\begin{array}{c}* \text { South-east } \\
(\mathbf{\%})\end{array}$ \\
\hline Sector & & & & \\
Rural & & & & 67.9 \\
Urban & 67.0 & 66.8 & 33.0 & 33.1 \\
Total & 33.0 & 33.2 & 100.0 & 100.0
\end{tabular}

Marital status

Married

Single

3.0

97.8

2.0

0.0

Widowed

1.0

Divorced

1.0

0.2

96.3

96.3

$3.3-2.8$

Divorced

Educational level of respondent

University degree

Polytechnic/diploma

Secondary school not completed

7.5

1.8

No formal education

1.5

17.0
16.0
52.8
9.2
4.5
0.5

10.5

9.8

55.2

16.8

7.2

0.5

0.5

0.4

Income of respondent(\$)

(estimated)

\$339 and above

\$277-338.9

$\$ 92.5-277.3$

$\$ 30.8-92.4$

Don't know

No income

1.0
0.8
14.0
21.0
37.3
26.0

1.5

2.3

18.5

32.0

11.8

0.5

Occupation of respondent

\begin{tabular}{lllll} 
Farmer & 4.0 & 0.8 & 2.0 & 2.3 \\
Trader & 44.3 & 37.8 & 43.0 & 41.7 \\
Employed by Government & 12.5 & 15.0 & 15.5 & 14.3 \\
Artisan & 5.5 & 5.8 & 4.5 & 5.3 \\
Religious leader & 0.0 & 0.0 & 1.0 & 0.3 \\
Professional* & 2.5 & 1.0 & 1.8 & 1.8 \\
Unemployed & 20.3 & 33.0 & 24.0 & 25.8 \\
Others & 11.0 & 6.8 & 8.2 & 8.7 \\
\hline
\end{tabular}

Note: Calculation for each state was based on 400 subjects while that of the South-east was based on 1200 subjects. ** Average of the three States. $\%=$ percentage 


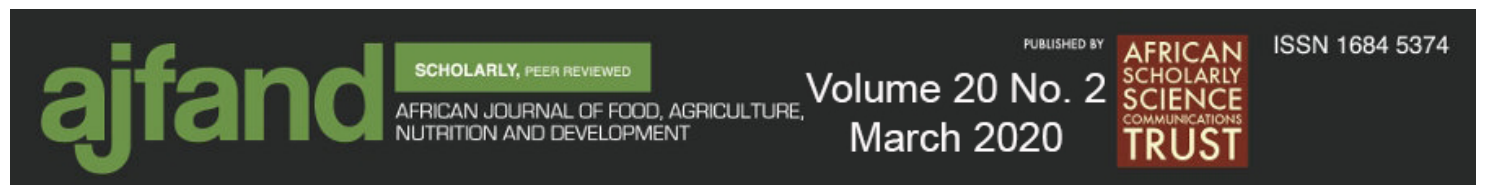

Table 2: Percentage of food group consumption among subjects in the three States and Southeast

\begin{tabular}{|c|c|c|c|c|}
\hline Food groups & $\operatorname{Imo}(\%)$ & Enugu (\%) & Anambra (\%) & South-east (\%) \\
\hline Cereals & 91.87 & 91.5 & 92.8 & 92.0 \\
\hline $\begin{array}{l}\text { Vit A rich } \\
\text { vegetables and } \\
\text { tubers }\end{array}$ & 57.2 & 38.8 & 46.8 & 47.6 \\
\hline $\begin{array}{l}\text { White tuber and } \\
\text { roots }\end{array}$ & 84.8 & 69.5 & 81.8 & 78.7 \\
\hline $\begin{array}{l}\text { Dark green } \\
\text { vegetables }\end{array}$ & 75.2 & 35.5 & 55.0 & 55.2 \\
\hline Other vegetables & 42.8 & 30.8 & 25.0 & 32.8 \\
\hline Vit A fruits & 11.5 & 11.8 & 8.2 & 10.5 \\
\hline other fruits & 17.2 & 16.5 & 20.2 & 18.0 \\
\hline Organ meat & 4.5 & 0.5 & 0.5 & 1.8 \\
\hline Flesh meat & 53.2 & 57.0 & 64.2 & 58.2 \\
\hline Eggs & 9.2 & 4.8 & 5.5 & 6.5 \\
\hline Fish & 86.5 & 70.2 & 73.0 & 76.6 \\
\hline $\begin{array}{l}\text { Legumes and } \\
\text { nuts }\end{array}$ & 50.8 & 59.2 & 51.5 & 53.8 \\
\hline $\begin{array}{l}\text { Milk and milk } \\
\text { products }\end{array}$ & 57.8 & 45.2 & 55.5 & 52.8 \\
\hline Oils and fats & 98.2 & 97.2 & 98.5 & 98.0 \\
\hline
\end{tabular}

Note: Calculation for each state was based on 400 subjects while that of the South-east was based on 1200 subjects. The fourteen food groups were used for individual dietary assessment while sixteen food groups are used for the household dietary assessment [19], $\%=$ percentage. A frequency table and cross-tabulation were used to analyze the fourteen food groups 


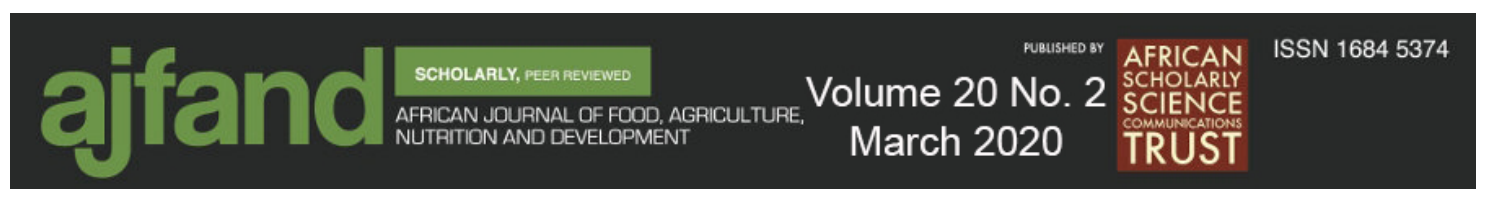

Table 3: Dietary Diversity Scores and Dietary Diversity Terciles in the three States and South-east

\begin{tabular}{lcccc}
\hline Dietary diversity scores & Imo $\mathbf{( \% )}$ & $\begin{array}{l}\text { Enugu } \\
(\%)\end{array}$ & $\begin{array}{l}\text { Anambra } \\
(\%)\end{array}$ & $\begin{array}{c}\text { South-east } \\
(\%)\end{array}$ \\
\hline 2 & 0 & 0.2 & 0.5 & 0.2 \\
3 & 1.2 & 2.5 & 1.0 & 1.6 \\
4 & 6.0 & 6.0 & 5.2 & 5.8 \\
5 & 12.8 & 14.0 & 13.5 & 13.4 \\
6 & 22.2 & 19.5 & 20.0 & 20.6 \\
7 & 22.0 & 20.0 & 24.0 & 22.0 \\
8 & 14.8 & 18.0 & 18.8 & 17.2 \\
9 & 8.8 & 13.2 & 12.2 & 11.4 \\
10 & 2.5 & 4.8 & 4.5 & 3.9 \\
11 & 9.8 & 1.8 & 0.5 & 3.9
\end{tabular}

Dietary diversity terciles

$\begin{array}{lllcl}\text { Low (1-4 food groups) } & 2.4 & 2.9 & 2.3 & 7.6 \\ \text { Medium (5-9 food groups) } & 26.8 & 28.3 & 29.5 & 84.6 \\ \text { High (10-14 food groups) } & 4.1 & 2.2 & 1.6 & 7.8\end{array}$

Sample size for each state was 400 , south east- $1200, \%=$ percentage. Frequency table and cross tabulation and chi-square was used to analyse the fourteen food groups and the terciles. The Dietary Diversity Score (DDS) of individual subjects ranged from 2 to 11 . The dietary diversity of highest frequencies were $7(22.0 \%), 6(20.6 \%), 8(17.2 \%)$ $5(13.4 \%)$ and $9(11.4 \%)$. The proportion of the subjects with the scores in each of the three tercile categories of low, medium/average, and high for the South-east was $7.6 \%$, $84.6 \%$ and $7.8 \%$, respectively

Table 4: Comparison of dietary diversity scores (DDS) of respondents in the three states and sectors

\begin{tabular}{llllll}
\hline State & $\mathbf{N}$ & Minimum & Maximum & Mean & SD \\
\hline Imo state & 400 & 3.00 & 11.00 & 7.10 & 1.99 \\
Enugu state & 400 & 2.00 & 11.00 & 6.89 & 1.78 \\
Anambra state & 400 & 2.00 & 11.00 & 6.89 & 1.62 \\
Sector & & & & & \\
Urban & 397 & 3.00 & 11.00 & 7.04 & 2.52 \\
Rural & 803 & 2.00 & 11.00 & 6.90 & 2.43 \\
\hline Total & 1200 & 2.33 & 11 & 6.96 & 1.80 \\
\hline
\end{tabular}

$\mathrm{N}=$ Number, $\mathbf{S D}=$ Standard deviation. Cross tab and chi-square tests were used to analyzed the difference between states. A t-test revealed a significant $(\mathrm{t}=6.23, \mathrm{p}<.001)$ mean difference between sectors 


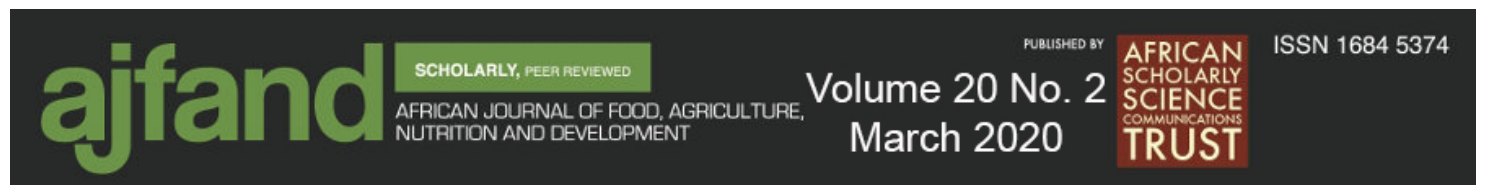

Table 5: BMI of mothers and diet diversity score in the South-east

\begin{tabular}{|c|c|c|c|}
\hline BMI & Low DDS (\%) & Medium DDS (\%) & High DDS (\%) \\
\hline Underweight & 0.0 & 70.0 & 30.0 \\
\hline Normal & 1.7 & 78.1 & 20.2 \\
\hline Overweight & 1.7 & 79.2 & 19.1 \\
\hline Obese & 2.3 & 80.1 & 17.6 \\
\hline
\end{tabular}

Note: Sample size- $1200, \%=$ percentage. There was no relationship observed between dietary diversity scores and maternal BMI $(\mathrm{P}>0.05)$. Correlation analysis showed that there was a negative correlation between dietary diversity and BMI $(r=-.02, \mathrm{p}>.05)$ 


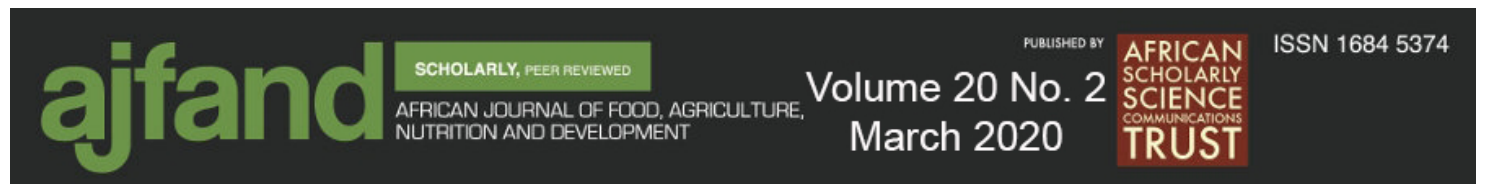

\section{REFERENCES}

1. Savy M, Martin-Prevel Y, Sawadogo P, Kameli Y and F Delpeuch Use of variety/diversity scores for dietary quality measurement: relation with nutritional status of women in a rural area in Burkina Faso. Eur J Clin Nutr. 2005; 59 (5):703-716.

2. Ruel MT Operationalizing dietary diversity. A review of measurement issues and research priorities. $J$ Nutr. 2003; 133:3911-3926.

3. Kant AK, Schatzkin A, Harris TB, Ziegler RG and G Block Dietary diversity and subsequent mortality in the first national health and nutrition examination survey epidemiologic follow-up study. Am J Clin Nutr. 1991; 57:434-40.

4. Krebs-Smith SM, Smiciklas-Wright H, Guthrie HA and J Krebs-Smith The effects of variety in food choices on dietary quality. J Amer Dietetic Assoc 1987; 87: 897-903.21.

5. Arimond M and MT Ruel Dietary diversity is associated with child nutritional status: Evidence from 11 demographic and health surveys. Washington/ International Food Policy Research Institute. 2004.

6. Thiele S, Mensink GB and R Beitz Determinants of diet quality. Public Health Nutr. 2004; 7(1): 29-37.

7. Underwood BA A life cycle micronutrient perspective for women's health. J. Amer Society Clinic Nutr. 1998; 81 (5): 1188-1193.

8. Maziya-Dixon BB, Akinyele IO, Oguntona EB, Nokoe S, Sanusi RA and E Harris Nigeria food consumption and Nutrition Survey 2001-2003 (Summary). International Institute for Tropical Agriculture (IITA); Ibadan, Nigeria. 2004.

9. Lartey A Nutrition in promoting the public's health: Strategies, Principles and Practice. Maternal \& Child Nutr. 2008; 5(1): 95-100.

10. Kennedy $\mathbf{E}$ and $\mathbf{L}$ Meyers Dietary reference intakes: development and uses for assessment of micronutrient status of women-a global perspective. Am. J. Clin. Nutr. 2005; 81:194-1197.

11. Kant AK, Schatzkin A, Harris TB, Ziegler RG and G Block Dietary diversity and subsequent mortality in the First National Health and Nutrition Examination Survey Epidemiologic Follow-Up Study. Am J Clin Nutr. 1993; 57:434-440.

12. Akerele $\mathbf{D}$ and $\mathbf{A O}$ Kehinde Demand for Diverse Diets: Evidence from Nigeria. Paper prepared for presentation at the $89^{\text {th }}$ Annual Conference of the Agricultural Economics Society, University of Warwick, United Kingdom13-15 April 2015. 


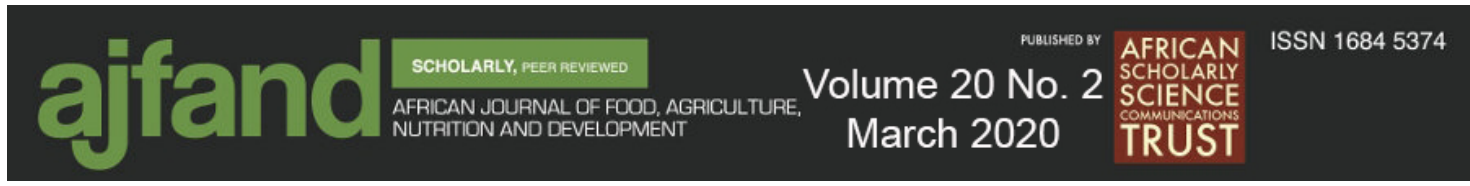

13. Muhammad-Lawal A, Ibrahim HK, Oloyede WO, Belewu KY and TA Adesina Assessment of Dietary Diversity and Food Calorie Consumption among Rural Households in Kwara State, Nigeria. Applied Trop Agric. 2017; 22(1): 134-141.

14. Sanusi RA An assessment of dietary diversity in six Nigerian states. Afr J Biomed Res. 2010; 13: 161-167.

15. Onyeji GN and RA Sanusi Diet quality of women of childbearing age in South-east Nigeria. Nutr Food Science 2018; 48(2): 348-336.

16. Ekong FU Women and development process in Nigeria: a case study of rural women in organizations in community development in Cross River state. Herald $J$ of Geography and Regional Planning. 2013; 2(2): 098-104.

17. Frankfort-Nachimias $\mathbf{C}$ and $\mathbf{D}$ Nachimias Research methods in social Sciences: Fourth Edition. Published by Edward Arnold Ltd, Kent, England. 1992; 97- 426.

18. Spiegel Murray and R Schaum Outline of theory and problems of statistics. Schaum Pub. Co., 1961.

19. Food and Agriculture Organization (FAO). Guidelines for measuring Household and individual dietary diversity. FAO Nutrition and consumer Protection Division, with support from EC/FAO Food Security Information for Action Programme and the food and Nutrition Technical Assistance (FANTA) project. 2007. http://wwwfoodsec.org/tr/nut/guidelnes.pdf. Visited on March 2010.

20. La Vecchia C, Negri E, Franceschi S, Parazzini F and A Decarli Differences in dietary intake with smoking, alcohol, and education. Nutr Cancer. 1997; 17: 297-304.

21. McCullough ML, Feskanich D, Stampfer MJ, Giovannucci EL, Rimm EB, Hu FB, Spiegelman D, Hunter DJ, Colditz GA and WC Willett Diet quality and major chronic disease risk in men and women: moving toward improved dietary guidance. Am J Clin Nutr. 2002;76:1261-1271.

22. Kant AK, Schatzkin A and RG Ziegler Dietary diversity and subsequent causespecific mortality in the NHANES I epidemiologic follow-up study. $J$ Am Coll Nutr. 1995; 14: 233 - 238.

23. Hodgson JM, Hsu-Hage B and ML Wahlqvist Food variety as a quantitative descriptor of food intake. Ecology Food Nutr. 1994; 32: 137-148.

24. International Food Policy Research Institute. Value chain for nutrition. Leveraging agriculture for improving nutrition and health. Brief 4. IFPRI 2020 International Conference, New Delhi, India; 2011. 


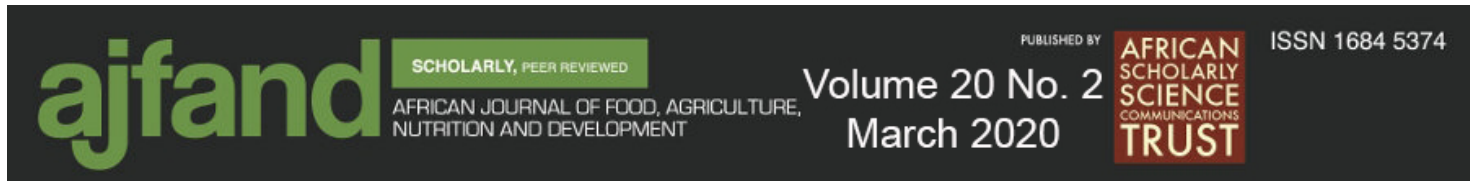

25. Micronutrient Initiative. Vitamin and mineral deficiency A global progress report. Ottawa: Micronutrient Initiative; 2004. Accessed November 292018. Available: http://www.micronutrient.org/CMFiles/PubLib/VMd-GPREnglish1KWW-3242008-681.pdf

26. Black RE, Allen LH, Bhuttam ZA, Caulfield LE, De Onis M and M Ezatti Maternal and child under nutrition: Global and regional exposures and health consequences. Lancet. 2008; 371:243-260.

27. United Nations System Standing Committee on Nutrition. 6th Report on the World Nutrition Situation: Progress in Nutrition; 2010. Accessed November 29, 2018. Available:

http://www.unscn.org/files/Publications/RWNS6/report/SCN report.pdf

28. Nupo SS, Oguntona CRB, Onabanjo OO and EO Fakoya Dietary diversity scores and nutritional status of women in two seasons in rural areas of Ogun state, Nigeria. Nutr Food Sci. 2013; 43(1): 60-67.

29. Agada M O and $\mathbf{E}$ M Igbokwe Dietary diversity of rural households in North Central Nigeria. European J Nutr Food Safety. 2015;5(3): 150-155, Article no.EJNFS. 2015.014.

30. Ukegbu O Patricia and C Ekebisi Assessing dietary diversity score and nutritional status of rural adult women in Abia State, Nigeria. Food Sci Nutr Technol 2016; 1(1) : 000106.

31. Labadarios L, Steyn NP and $\mathbf{J}$ Nel How diverse is the diet of adult South Africans. Nutr J. 2011; 10:33 DOI: 10. 1186/1495-2891-10-33.

32. Kennedy G, Pedro MR, Seighieri C, Nantel G and ID BrouwerDietary diversity score is a useful indicator of micronutrient intake in non-breast-feeding Filipino children. J Nutr. 2007; 137(2):472-477.

33. Torheim LE, Ouattara F, Diarra MM, Thiam FD, Barikmo I, Hatloy A and A Oshaug Nutrient adequacy and dietary diversity in rural Mali: association and determinants. Eur J Clin Nutr. 2004; 58: 594-604.

34. Arroyo PM Energetic density, diversity of diets and familial income in rural and urban households of Mexico. Gac Med Mex. 2007; 143(4): 301-307.

35. Roche ML, Creed-Kanashiro HM, Tuesta I and HV Kuhnlein Traditional food diversity predicts dietary quality for the Awajuin in the Peruvian Amazon. Public Health Nutr. 2008; 11: 457-465.

36. Delisle $\mathbf{H}$ Patterns of urban food consumption in developing countries: perspective from the 1980's FAO, Rome. 1990. (Available at www.fao.org/es/ESN/nutrition/national urban publication en.stm. Accessed November 29, 2018. 


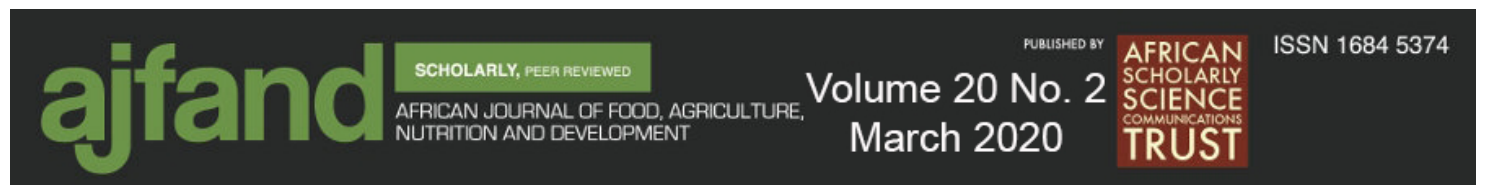

37. Arimond M, Torheim E, Wiesmann D, Joseph M and A Carriquiry Dietary diversity as a measure of women's diet quality in resource-poor areas: results from rural Bangladesh site. Washington, DC: Food and Nutrition Technical Assistance (FANTA) Project/Academy for educational Development (AED), 2008.

38. Arimond M and MT Ruel A report on the investigation into recurrent epidemics of pellagra in Kuito-Angola. Food and Nutrition Technical Assistance (FANTA) project, Academy for Educational Development (AED) and United States Agency for International Development (USAID). Washington D.C.; 2002.

39. Savy M, Martin-Prével Y, Danel P, Traissac P, Dabiré H and F Delpeuch Are dietary diversity scores related to the socio-economic and anthropometric status of women living in an urban area in Burkina Faso? Public Health Nutr.2008 Feb; 11.2: 132-141.

40. Savy M, Martin-Prével Y, Sawadogo P, Kameli Y and F Delpeuch Use of variety/diversity scores for diet quality measurement: relation with nutritional status of women in a rural area in Burkina Faso. Eur J Clin Nutr. 2005; 59(5):703716.

41. Steyn NP, Nantel G, Kennedy G and D Labandarios Food variety and dietary diversity scores in children: are they good indicators of dietary adequacy. Pub Health Nutr. 2006; 9(5): 644-650.

42. Ishara $\mathbf{M}$ and $\mathbf{J}$ Rathnayake Maternal employment and income affect dietary calorie adequacy in households in Sri Lanka. Food Nutr Bull. 2005; 26: 222-229.

43. Vakili1 M, Abedi $\mathbf{P}$, Sharifi $M$ and $M$ Hosseini Dietary diversity and its related factors among adolescents: A survey in Ahvaz-Iran. Global J Health Sc. 2013; 5: 2. 

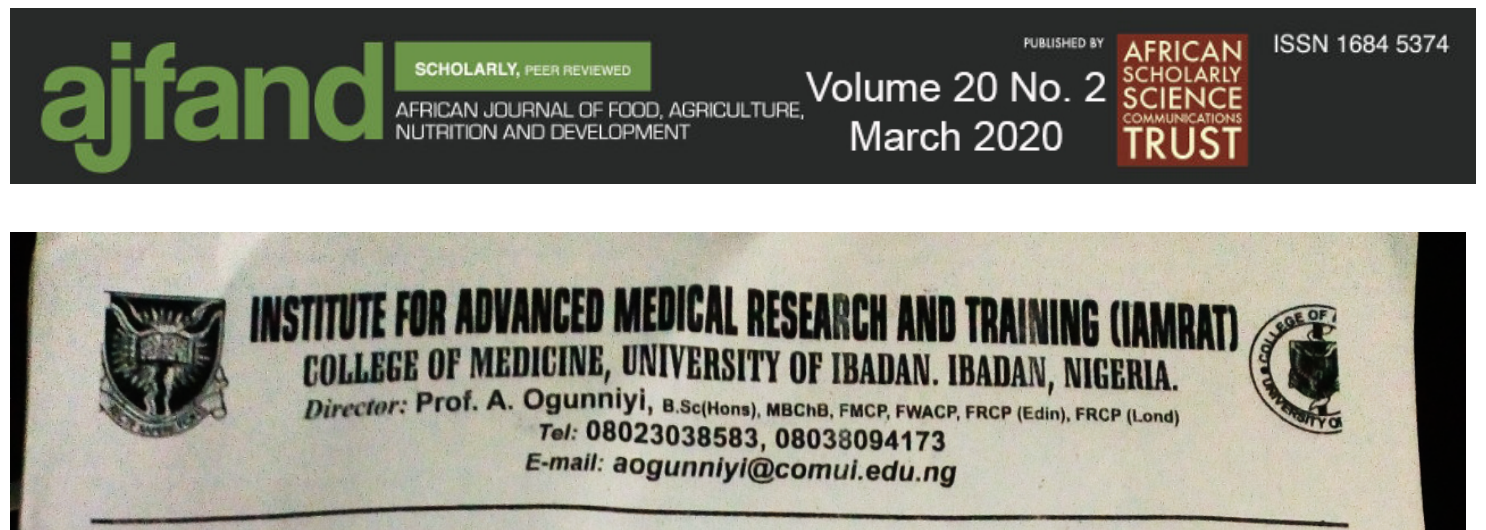

\section{UIUCH EC Registration Number: NHREC/05/01/2008a \\ NOTICE OF FULL APPROVAL AFTER FULL COMMITTEE REVIEW}

Re: An Assessment of Diet Quality and Diversity of Diets in the South East Geo-Political Zone of Nigeria

UI/UCH Ethics Committee assigned number: UL/EC/13/0065

Name of Principal Investigator:

Gertrude N. Ozyeji

Address of Principal Investigator:

Department of Human Nutrition,

College of Medicine,

University of Ibadan, Ibadan

Date of receipt of valid application: 04/03/2013

Date of meeting when final determination on ethical approval was made: 16/05/2013

This is to inform you that the research described in the submitted protocol, the consent forms, and other participant information materials have been reviewed and given full approval by trie UIUCH Ethics Committee.

This approval dates from $16 / 05 / 2013$ to $15 / 05 / 2014$. If there is delay in starting the research, please inform the UI/UCH Ethics Committee so that the dates of approval can be adjusted accordingly. Note that no participant accrual or activity relaied to this research may be conducted outside of these dates. Ali informed consent forms used in this study must carry the $\mathrm{UI} / \mathrm{UCH}$ EC assigned number and duration of UI/UCH EC approval of the study. It is expescted that you submit your annual report as well as an annual request for the project renewal to the UI/UCH EC eariy in order to obtain renewal of your approval to avoid disruption of your research.

The National Code for Health Research Ethics requires you to comply with all institutional guidelines, rules and regulations and with the tenets of the Code including ensuring that all adverse events are reported promptly to the UI/UCH EC. No changes are permitted in the research without prior approval by the UI/UCH EC except in circumstances outlined in the Code. The UI/UCH EC reserves the right to conduct compliance visit to your research site , without previous notification.

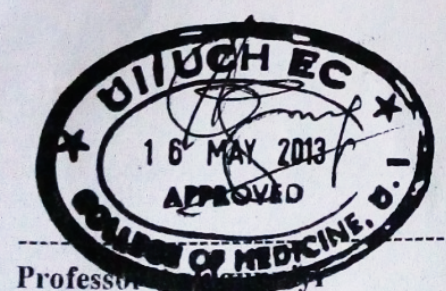

Director, IAMRAT

Chairman, UI/UCH Ethics Cominittee

E-mail: uiuchirc@yahoo.com

- Druo and Cancer Research Unit Environmental Sciences \& Toxicolonv a Ganotics \& Cancar Recearch o Mnlarular Fntrmmina 